\title{
A Rare Cause of Food Impaction: Heterotopic Gastric Mucosa
}

\author{
Inês Marques de Sáa Ana Marques ${ }^{b, c, d}$ Pedro Pimentel-Nunes ${ }^{a, e}$ \\ ${ }^{a}$ Department of Gastroenterology, Portuguese Oncology Institute of Porto, Porto, Portugal; ${ }^{b}$ IPATIMUP Diagnostics, \\ Institute of Molecular Pathology and Immunology of Porto University, Porto, Portugal; ' ${ }^{C}$ Department of Pathology, \\ Centro Hospitalar Universitário de São João EPE, Porto, Portugal; ${ }^{d}$ Department of Pathology, Faculty of Medicine, \\ University of Porto, Porto, Portugal; ${ }^{~}$ CINTESIS (Center for Health Technology and Services Research), Faculty of \\ Medicine, University of Porto, Porto, Portugal
}

Keywords

Heterotopic gastric mucosa $\cdot$ Stenosis · Food impaction

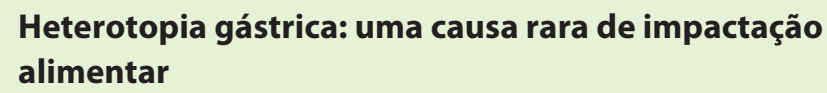

\section{Palavras Chave}

Heterotopia gástrica · Estenose · Impactação alimentar

A 22-year-old healthy male was referred to the Endoscopy Unit due to food impaction. He was having difficulty swallowing solid food for the last 2 years. Esophagogastroduodenoscopy (EGD) revealed impacted meat in the cervical esophagus at $18 \mathrm{~cm}$ from the incisors, which was removed with a Roth net (Fig. 1). After endoscopic resolution, EGD revealed an almost circular and columnar inlet patch between 17 and $19 \mathrm{~cm}$ from the incisors involving more than $75 \%$ of the esophageal circumference. The lower margin of the inlet had mucosal injury and a ring stricture allowing passage for the endoscope with some difficulty (Fig. 2). The biopsies of the inlet showed gastric columnar mucosa with fundic type glands (Fig. 3), and biopsies of the remaining esophageal mu-

karger@karger.com www.karger.com/pjg

Karger" (c) 2021 Sociedade Portuguesa de Gastrenterologia Published by S. Karger AG, Basel

This is an Open Access article licensed under the Creative Common Attribution-NonCommercial-4.0 International License (CC BY-NC) (http://www.karger.com/Services/OpenAccessLicense), applicable to the online version of the article only. Usage and distribution for commercial purposes requires written permission. cosa were unremarkable excluding eosinophilic esophagitis. After 3 months on esomeprazole $20 \mathrm{mg}$ once daily, the patient had clinically improved with resolution of the ring stricture on EGD. Using narrow band imaging, the columnar inlet revealed regular circular/oval mucosa surrounded by regular vessels (Fig. 4), suggestive of oxyntic type mucosa. These findings are consistent with heterotopic gastric mucosa in the cervical esophagus with stenosis. Due to the risk of symptoms relapse with protonpump inhibitor (PPI) withdrawal, therapeutic options, namely argon plasma coagulation (APC) and long-term PPI, were discussed with the patient. Long-term treatment with esomeprazole $20 \mathrm{mg}$ with 6-12 months clinical follow-up was decided. Ablation of the inlet patch with APC or radiofrequency (RFA) was reserved for refractory symptoms.

Heterotopic gastric mucosa is an island of ectopic gastric mucosa located in the cervical esophagus below the upper esophageal sphincter. Its prevalence has been reported to range between 0.1 and $11 \%$ in various studies [1]. Although it is accepted as being a congenital anomaly, a theory postulates that heterotopic gastric mucosa results from metaplastic transformation of the squamous epithelium due to chronic acid injury like in Barrett's 
1

Fig. 1. Endoscopy image: impacted meat on the upper third of the esophagus.

Fig. 2. Endoscopy image: mucosal injury and a ring stricture on the upper third of the esophagus.
2

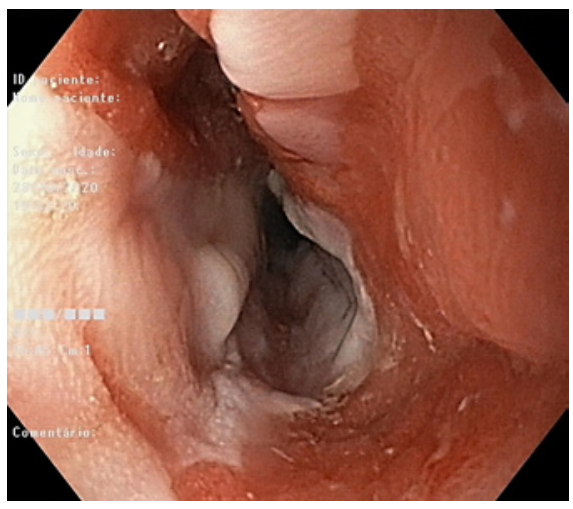

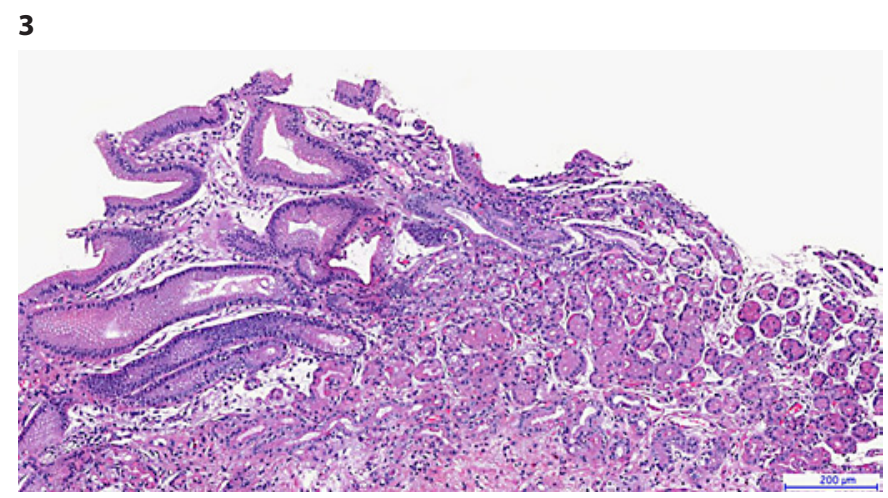

4

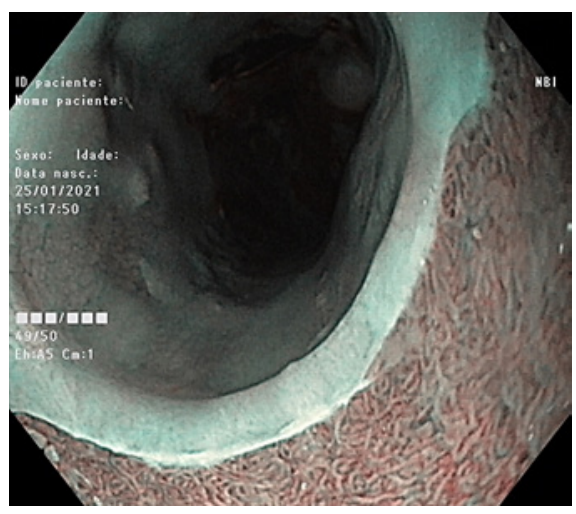

Fig. 3. Pathology image: fragments of mucosa lined by foveolar epithelium with fundic type glands.

Fig. 4. Endoscopy image: circular and columnar inlet patch on the upper third of the esophagus with NBI after proton-pump inhibitor.

esophagus [1]. Generally, these lesions present as an asymptomatic incidental finding. However, few case reports have indicated that heterotopic gastric mucosa can produce laryngopharyngeal symptoms and complications like stenosis or malignant transformation $[1,2]$. Symptomatic or complicated heterotopic gastric mucosa has to be managed either medically and/or endoscopically. While PPI is recommended as the first-line treatment since it is more widely available and safer [2], endoscopic ablation techniques are considered for symptoms unresponsive to PPI. However, APC and RFA have the potential risk of stenosis when the inlet patch occupies more than a third of the esophageal circumference [2-4]. In case of extensive ring formation, esophageal dilation with acid suppression is also an effective treatment [5]. Endoscopic mucosal resection or submucosal dissection have been used for inlet patches with malignant transformation [2].

Heterotopic gastric mucosa is generally ignored by endoscopists because it is considered benign and asymp- tomatic. Nevertheless, gastroenterologists should take this entity into account during dysphagia workup since it can rarely cause symptoms.

\section{Statement of Ethics}

Informed patient consent was obtained for publication of the case details.

\section{Conflict of Interest Statement}

The authors have no conflicts of interest to declare.

Funding Sources

None. 
Data collection was performed by Inês Marques de Sá, Ana Marques, and Pedro Pimentel-Nunes. Draft of the article was performed by Inês Marques de Sá. Article review was performed by Pedro Pimentel-Nunes.

\section{References}

1 Chong VH. Clinical significance of heterotopic gastric mucosal patch of the proximal esophagus. World J Gastroenterol. 2013 Jan;19(3):331-8.

2 Cock C, Hamarneh Z. Gastric inlet patches: symptomatic or silent? Curr Opin Otolaryngol Head Neck Surg. 2019 Dec;27(6):453-62.
3 Alberty JB, Chanis R, Khoshoo V. Symptomatic gastric inlet patches in children treated with argon plasma coagulation: a case series. J Interv Gastroenterol. 2012 Apr;2(2):91-3.

4 Kristo I, Rieder E, Paireder M, Schwameis K, Jomrich G, Dolak W, et al. Radiofrequency ablation in patients with large cervical hetero- topic gastric mucosa and globus sensation: closing the treatment gap. Dig Endosc. 2018 Mar;30(2):212-8.

5 Ainley EJ. High oesophageal web formation in association with heterotopic gastric mucosa (the gastric inlet patch): a small case series. Frontline Gastroenterol. 2011 Apr;2(2):117-23. 